\title{
Increased thrombin generation after acute versus chronic coronary disease as assessed by the thrombin generation test
}

Josune Orbe, Maite Zudaire, Rosario Serrano, Isabel Coma-Canella, Sara Martínez de Sizarrondo, Jose A. Rodríguez, Jose A. Páramo

Atherosclerosis Research Laboratory, Division of Cardiovascular Sciences, CIMA, University of Navarra, Pamplona, Spain

\begin{abstract}
Summary
Atherosclerosis is the most common pathophysiologic substrate of coronary artery disease (CAD). Whereas plaque progression and arterial remodeling are critical components in chronic CAD, intracoronary thrombosis over plaque disruption is causally related to acute CAD. It was the objective of this study to investigate the differences between prior acute $C A D$ and chronic $C A D$ by a simple global coagulation assay measuring thrombin generation. A cross-sectional study involving 15 healthy controls, 35 patients with chronic stable CAD, and 60 patients after an episode of acute myocardial infarction (AMI) was performed. Thrombin generation was measured between three and II months after the initial diagnosis (mean 6 months) by a commercially available fluorogenic assay (Technothrombin TGA). In each patient the lag phase, velocity index and peak thrombin were obtained from the thrombogram profile. Tradi-
\end{abstract}

\section{Keywords}

Thrombin, acute myocardial infarction, coronary syndrome tional cardiovascular risk factors were recorded, and the inflammatory markers, fibrinogen and hs-C-reactive protein were determined. Compared with stable CAD patients, showing normal thrombograms, those with previous AMI showed earlier lag phase $(p<0.05)$ and significant increase of both the velocity index $(p<0.00 \mathrm{I})$ and peak thrombin $(p<0.05)$, indicating faster and higher thrombin generation in the AMl group. Differences in thrombin generation between stable and acute CAD patients remained significant $(p<0.00 I)$ after adjusting for conventional CAD risk factors (age, gender, diabetes, hypertension, smoking, and hypercholesterolemia). In conclusion, patients with a previous history of acute $C A D$ showed earlier, faster and higher thrombin generation than stable chronic CAD patients. The thrombin generation test may be of clinical value to monitor hypercoagulable/vulnerable blood and/or guide therapy in CAD.

\section{Introduction}

Thrombin generation is a pivotal step in haemostasis leading to the conversion of fibrinogen to fibrin $(1,2)$. Despite its clear relevance in the pathogenesis of thrombotic disorders, no direct reliable test is available and indirect measurement of thrombin (e.g. activation peptides released from the zymogen or enzymeinhibitor complexes) is generally performed. Recently, a new methodology has become available to assess the endogenous thrombin potential in vivo $(3,4)$. Thrombin activity can be registered by continuous measuring of chromogenic or fluorescent substrate cleavage, resulting in a thrombin generation curve. The endogenous thrombin potential is obtained upon activation of coagulation by small amounts of tissue factor (TF) and phospholipids, and it has been associated with risk of venous thromboembolism and hypercoagulable states $(5,6)$.

Atherosclerosis is the most common pathophysiologic substrate of coronary artery disease (CAD), which can manifest clinically as an acute or chronic disorder. Inflammation plays a major role in all stages of atherogenesis but, whereas atheroma plaque progression and arterial remodelling are critical components in stable $\mathrm{CAD}$, disrupted plaques provoke thrombosis underlying acute coronary syndromes, namely unstable angina and acute myocardial infarction (AMI) $(7,8)$. The disrupted plaque represents an stimulus to both thrombosis and coagulation since thrombin activates platelets and converts 
Table I: Baseline characteristics, cardiovascular risk factors and inflammatory markers in the studied population. Values are presented as mean \pm SD.

\begin{tabular}{|c|c|c|c|}
\hline & $\begin{array}{l}\text { Stable CAD } \\
(\mathrm{n}=35)\end{array}$ & $\begin{array}{l}\text { Previous AMI } \\
(n=60)\end{array}$ & $\mathbf{P}$ \\
\hline Age (years) & $62.6 \pm 10.2$ & $50.7 \pm 7.2$ & 0.001 \\
\hline Gender (M/F) & $32 / 3$ & $52 / 8$ & Ns \\
\hline Dyslipidemia $(\mathrm{Y} / \mathrm{N})$ & $32 / 3$ & $44 / 16$ & 0.033 \\
\hline Smoking $(\mathrm{Y} / \mathrm{N})$ & $7 / 28$ & $44 / 16$ & 0.001 \\
\hline Obesity $(\mathrm{Y} / \mathrm{N})$ & $17 / 18$ & $14 / 46$ & 0.011 \\
\hline $\mathrm{BMI}\left(\mathrm{Kg} / \mathrm{m}^{2}\right)$ & $29.5 \pm 2.7$ & $27.6 \pm 3.9$ & 0.017 \\
\hline $\mathrm{SBP}(\mathrm{mm} \mathrm{Hg})$ & $131.9 \pm 19.8$ & $131.7 \pm 19.9$ & Ns \\
\hline$\overline{\mathrm{DBP}}(\mathrm{mm} \mathrm{Hg})$ & $74.9 \pm 14.0$ & $80.1 \pm 12.3$ & Ns \\
\hline Hypertension $(\mathrm{Y} / \mathrm{N})$ & $5 / 30$ & $10 / 50$ & Ns \\
\hline Glucose (mg/dl) & $129.4 \pm 59.5$ & $115.4 \pm 44.8$ & Ns \\
\hline Diabetes mellitus $(\mathrm{Y} / \mathrm{N})$ & $|4 / 2|$ & $14 / 46$ & Ns \\
\hline Total-cholesterol (mg/dl) & $166.1 \pm 44.7$ & $211.3 \pm 46.2$ & 0.001 \\
\hline LDL-cholesterol (mg/dl) & $92.0 \pm 31.4$ & $130.1 \pm 43.6$ & 0.001 \\
\hline HDL-cholesterol (mg/dl) & $48.5 \pm 15.5$ & $41.3 \pm 11.9$ & 0.017 \\
\hline Triglycerides $(\mathrm{mg} / \mathrm{dl})^{*}$ & $105.5(66)$ & $162.5(117)$ & 0.003 \\
\hline Anthypertensive $(\mathrm{Y} / \mathrm{N})$ & $30 / 5$ & $52 / 8$ & Ns \\
\hline Statins $(\mathrm{Y} / \mathrm{N})$ & $31 / 4$ & $51 / 9$ & Ns \\
\hline Antidiabetic $(\mathrm{Y} / \mathrm{N})$ & $13 / 22$ & $14 / 46$ & Ns \\
\hline Fibrinogen $(\mathrm{mg} / \mathrm{dl})$ & $359.3 \pm 88.5$ & $357.6 \pm 77.2$ & Ns \\
\hline hs-CRP $(\mathrm{mg} /)^{*}$ & $4.0(4.9)$ & $3.9(3.8)$ & Ns \\
\hline
\end{tabular}

fibrinogen to fibrin, characteristic of the "white" arterial thrombus (9).

The term "cardiovascular vulnerable patient" defines subjects susceptible to an acute coronary syndrome or sudden cardiac death based on plaque, blood or myocardial vulnerability $(10,11)$. Vulnerable blood (prone to thrombosis) plays an important role in the outcome of CAD (7). The importance of the coagulation system underlying plaque complications has been experimentally addressed by Karnicki et al. who demonstrated in a porcine model that blood factors must have a major role in thrombus propagation (12). Moreover, it has also been established that after an episode of unstable angina or AMI, a high proportion of patients show biochemical signs of coagulation activation in their blood (13-16), which may have a great impact in terms of recurrence and long-term mortality (17).

Therefore, we hypothesized that measurement of endogenous thrombin potential could differentiate stable from unstable coronary patients. To test this hypothesis, we performed a simple global coagulation assay, the thrombin generation test, in stable CAD and in a series of patients long after a prior episode of AMI.

\section{Patients and methods}

\section{Patients}

We studied 95 consecutive patients $(90 \%$ men, mean age 56 years) with CAD and no history of malignant or autoimmune disease, coagulation disorders, or presence of chronic renal insufficiency (creatinine level $\geq 124 \mu \mathrm{M}$ ), who were under observation at the Cardiology Department of the University Hospital (Pamplona, Spain)

In particular, the recruitment diagnosis was either previous AMI $(n=60)$ or stable angina $(n=35)$. Samples were taken between three and 11 months after the initial diagnosis (mean 6 months). Stable angina pectoris was defined as typical exertional angina associated with electrocardiographic horizontal or downslopping ST-segment depression $>1.5 \mathrm{~mm}$ during exercise. Patients with previous AMI were included if they had diagnostic ST-segment elevations and peak creatinin kinase-MB and tropo$\operatorname{nin}(18)$.

All patients were treated with aspirin indefinitely, and none of them was receiving oral anticoagulant treatment. A high proportion were also taking statins and antihypertensive therapy $(>80 \%)$ (Table 1).

Exclusion criteria were age $\geq 70$ years, treatment for restenosis, coronary artery bypass grafting, or percutaneous coronary intervention (PCI) within the previous six months, heart failure of New York Heart Association class $\geq 3$ or known malignant or inflammatory disorders.

As controls, a similarly aged group $(n=15,86 \%$ men, mean age 59 years) with no history of CAD or diabetes mellitus with normal physical examination and resting electrocardiogram was enrolled. 


\section{Assessment of cardiovascular risk factors}

The cardiovascular risk factors, diabetes mellitus, arterial hypertension and smoking habits were obtained in all patients. Patients were considered to be hypertensives if they had systolic blood pressure $\geq 140 \mathrm{~mm} \mathrm{Hg}$ and/or diastolic pressure $\geq 90 \mathrm{~mm} \mathrm{Hg}$ or were taking antihypertensive drugs. Subjects with a positive history of diabetes mellitus or with fasting glucose levels $\geq 126 \mathrm{mg}$ / $\mathrm{dl}$ were considered diabetic. Smoking was defined as "current smokers" or "non-smokers". Obesity was defined as body mass index (BMI) $\geq 30 \mathrm{~kg} / \mathrm{m}^{2}$. Dyslipidemia was diagnosed in the presence of at least one of the following measurements: total cholesterol $>200 \mathrm{mg} / \mathrm{dl}$, LDL-cholesterol $>130 \mathrm{mg} / \mathrm{dl}$, and HDL-cholesterol $<35 \mathrm{mg} / \mathrm{dl}$.

The study was approved by the local ethics committee and all subjects gave informed consent.

\section{Methods}

A fasting morning blood sample was taken from each patient. The biological parameters analyzed are listed in Table 1. All samples were stored at $2^{\circ} \mathrm{C}$ to $6^{\circ} \mathrm{C}$ and centrifuged within 2 hours at 2,000 rpm for 20 minutes ( $\mathrm{min}$ ). Citrated platelet-poor plasma (PPP) and serum were obtained and stored at $-40^{\circ} \mathrm{C}$, and all samples were measured within one month of sampling. The mean time between the initial diagnostic and blood sampling was six months (range 3-11 months).

\section{Inflammatory markers}

Plasma fibrinogen activity was measured by a clotting assay (CA-1500, Dade Behring, Marburg, Germany). High-sensitive-C reactive protein (hs-CRP) was assessed by immunoassay (Immulyte, Diagnostic Product Corporation, Los Angeles, CA, USA).

\section{Thrombin generation test}

Thrombin generation was determined in PPP according to the method described by Hemker et al. (3), on a SpectraMax fluor- ometer. Fluorescence intensity was detected at wavelengths of $390 \mathrm{~nm}$ (excitation filter) and $460 \mathrm{~nm}$ (emission filter). Briefly, $40 \mu \mathrm{l}$ of PPP were dispensed into 96-well microtiter plates, with each well containing $10 \mu \mathrm{l}$ of reagent (phospholipid micelles and tissue factor, rhTF $20 \mathrm{pM}$ ) and $50 \mu \mathrm{l}$ of the fluorogenic substrate. Sample measurement was performed for $60 \mathrm{~min}$ at $37^{\circ} \mathrm{C}$, in 1-min reading intervals. Evaluation was done automatically with the Technothrombin ${ }^{\circledR}$ TGA evaluation software to obtain calibrated thrombin concentration curves.

Three major parameters can be assessed in this test: the lag time (from the time point when $\mathrm{CaCl}_{2}$ and the phospholipid/rhTF is added until the first burst in thrombin formation), the velocity index (rate of thrombin formation per min, VI = peak thrombin/ peak time-lag time), and peak thrombin (maximum concentration of thrombin formed). The corresponding values obtained in a control group of 15 healthy subjects were:

- Lag time ( $\mathrm{min}): 8.3 \pm 0.7$

- Velocity index (nM/min): $182.5 \pm 25.9$

- Peak thrombin (nM): $497.4 \pm 37.3$

\section{Statistical analysis}

Continuous variables are expressed as mean \pm SD. Differences between mean values were assessed by ANOVA (for normally distributed variables) followed by Bonferroni test and by the non-parametric Kruskal-Wallis test for other variables. Categorical data were compared with chi $^{2}$-test. Additionally, the relationship between thrombin generation test parameters and clinical and analytical data was examined by Pearson correlation analysis. Analysis of covariance (ANCOVA) was used to compare groups for the adjustment of confounding variables. Analysis were performed using SPSS version 13.0 (SPSS Inc, Chicago, IL, USA). A p-value of $<0.05$ was considered statistically significant.

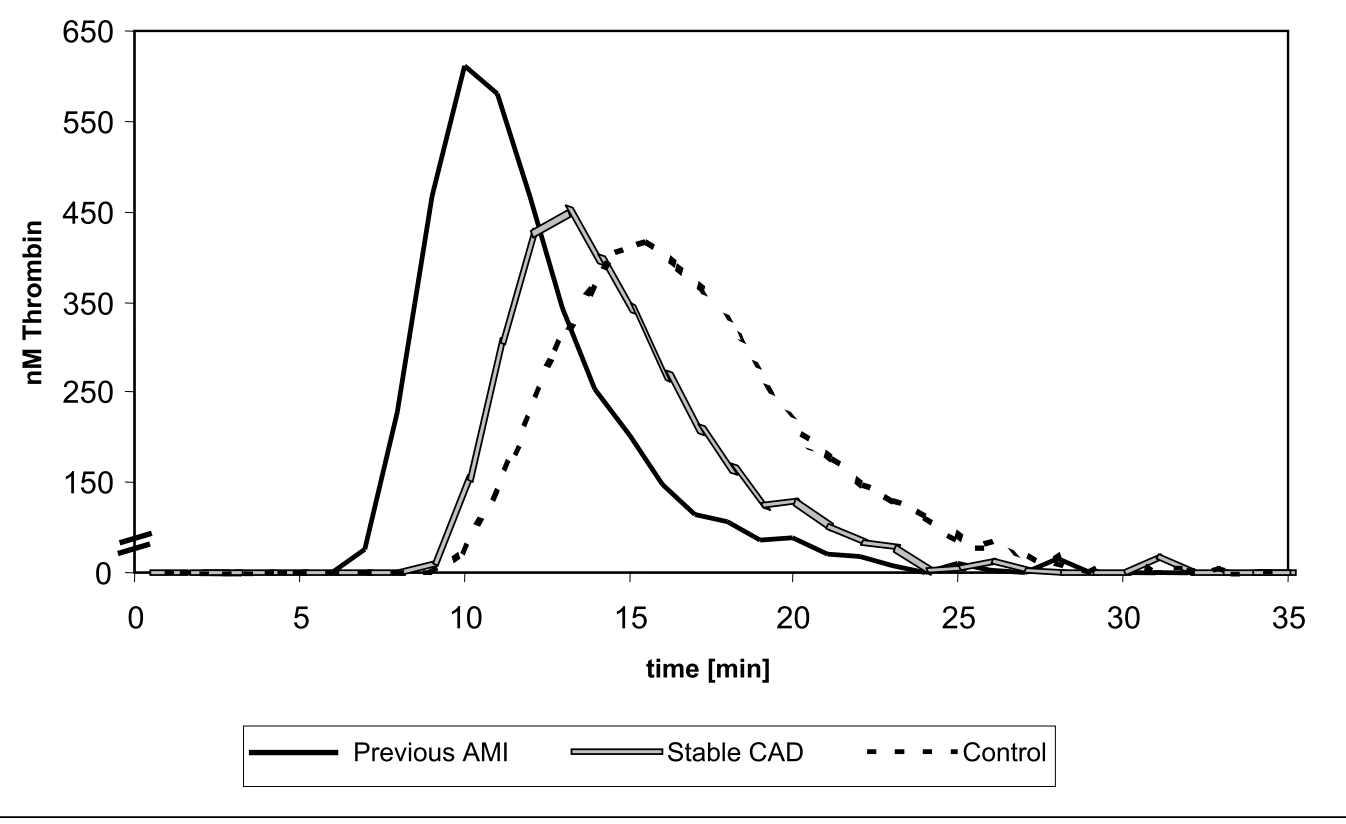

Figure I: A typical thrombogram profile as assessed by the thrombin generation tests in control subjects, stable CAD patients and previous AMI. 
Table 2: Differences in the thrombin generation values between stable CAD and AMI patients.

\begin{tabular}{|l|l|l|l|l|l|l|}
\hline & Stable CAD & Previous AMI & P† & Stable CAD & Previous AMI & P\# \\
\hline Lag phase $(\mathrm{min})$ & $10.1 \pm 4.3$ & $8.5 \pm 2.1$ & 0.076 & $10,2 \pm 0.7$ & $8,3 \pm 0.5$ \\
\hline Peak thrombin $(\mathrm{nM}) *$ & $472.5 \pm 40.1$ & $613.6 \pm 20.6$ & 0.001 & $429.5 \pm 43.1$ & $615.5 \pm 26.1$ & $<.045$ \\
\hline Peak time (min) & $14.3 \pm 5.8$ & $10.8 \pm 2.7$ & 0.004 & $14.6 \pm 0.9$ & $10.6 \pm 0.6$ & $<0.00 \mathrm{I}$ \\
\hline Velocity index (nM/min)* & $158.1 \pm 21.7$ & $269.2 \pm 21.0$ & 0.001 & $133.5 \pm 35.8$ & $296.3 \pm 22.8$ & $<0.00 \mathrm{I}$ \\
\hline * Logarithmically transformed. † Unadjusted values. \#After controlling for age, sex, obesity and dyslipidemia. & & \\
\hline
\end{tabular}

\section{Results}

\section{Baseline characteristics}

Baseline characteristics of the studied patients are shown in Table 1. Thirty-five patients had been diagnosed stable angina (mean age 62 years) and $60 \mathrm{AMI}$ (mean age 50.7 years), most of whom were men. The cardiovascular risk factors dyslipidaemia $(p<0.05)$, and smoking $(p<0.001)$ were more prevalent in the AMI group as compared with stable patients without differences in the percentage of diabetes and hypertension. The levels of total cholesterol $(p<0.001)$, LDL-cholesterol $(p<0.001)$, and triglycerides $(\mathrm{p}<0.01)$ were significantly higher in AMI patients, whereas no differences regarding antithrombotic and antiatherosclerotic therapy could be observed between groups.

As shown in Table 1, no significant differences in the levels of fibrinogen and hs-CRP were observed in stable versus AMI patients.

\section{Thrombogram results}

Figure 1 shows a typical thrombogram curve from controls, stable CAD and AMI patients as assessed by the thrombin generation test. Compared with stable CAD and controls, AMI patients had a higher peak thrombin and velocity index and reduced lag phase, indicating earlier, faster and increased thrombin gen- eration in the AMI group compared with stable disease (Table 2). In order to assess whether the observed differences in the thrombogram pattern could be related to either clinical or biological confounders, further ANCOVA analysis, controlling for age, sex obesity and dyslipidemia, revealed a statistical significant increase in the thrombin peak $(615.5 \pm 26.1$ vs. $429.5 \pm 43.1$, $\mathrm{p}<0.001)$, velocity index $(296.3 \pm 22.8$ vs. $133.5 \pm 35.8$, $\mathrm{p}<0.001)$, and reduced lag phase $(8.3 \pm 0.5 \mathrm{vs} .10 .2 \pm 0.7, \mathrm{p}<0.05)$ in AMI patients as compared with stable CAD (Table 2), again indicating earlier, faster and higher thrombin generation in the AMI group.

\section{Thrombin generation in relation to clinical characteristics in AMI patients}

Next, we tried to correlate the thrombogram results with the clinical and biological characteristics in the stable CAD and AMI groups (Table 3). A significant association could be demonstrated in stable CAD patients between either peak thrombin or velocity index and some traditional cardiovascular risk factors and inflammatory markers. The thrombin peak positively correlated with triglycerides $(r=0.53 p<0.01)$, fibrinogen $(r=0.58, p<0.05)$, glucose $(\mathrm{r}=0.52, \mathrm{p}<0.01)$ and hs-CRP $(\mathrm{r}=0.55, \mathrm{p}<0.05)$. In addition, the velocity index also correlated with triglycerides $(\mathrm{r}=0.41$, $\mathrm{p}<0.05)$, fibrinogen $(\mathrm{r}=0.53, \mathrm{p}<0.05), \mathrm{CRP}(\mathrm{r}=0.57, \mathrm{p}<0.05)$ and

Table 3: Correlations among thombin generation values in stable CAD and AMI patients.

\begin{tabular}{|l|l|l|l|l|l|l|}
\hline \multirow{2}{*}{} & \multicolumn{3}{|c|}{ Stable CAD } & \multicolumn{3}{c|}{ Previous AMI } \\
\cline { 2 - 7 } & Lag phase & Thrombin & Velocity index & Lag phase & Thrombin & Velocity index \\
\hline Age & 0.01 & 0.21 & 0.30 & -0.17 & 0.25 & 0.08 \\
\hline BMI & -0.10 & -0.08 & -0.18 & 0.14 & -0.04 & 0.03 \\
\hline SBP & -0.36 & 0.34 & $0.39 *$ & -0.10 & 0.03 & 0.10 \\
\hline DBP & -0.18 & 0.26 & 0.18 & -0.15 & -0.01 & 0.10 \\
\hline Cholesterol & -0.10 & 0.39 & 0.10 & 0.10 & -0.23 & -0.20 \\
\hline HDL-cholesterol & 0.13 & -0.13 & 0.01 & -0.26 & -0.11 & 0.10 \\
\hline LDL-cholesterol & 0.16 & -0.29 & -0.24 & 0.10 & -0.21 & -0.20 \\
\hline Glucose & -0.23 & $0.52^{* *}$ & 0.19 & -0.14 & 0.01 & -0.03 \\
\hline Triglycerides\# & $-0.38^{*}$ & $0.53^{* *}$ & $0.41^{*}$ & 0.20 & -0.06 & -0.13 \\
\hline Fibrinogen & -0.21 & $0.58^{*}$ & $0.53^{*}$ & 0.07 & -0.19 & -0.05 \\
\hline hs-CRP\# & -0.44 & $0.55^{*}$ & $0.57^{*}$ & -0.03 & 0.01 & 0.04 \\
\hline \# Logarithmically transformed variables. *P<0.05, ** $<0.01$. BMI=Body mass index; SBP= Systolic blood pressure; DBP= Diastolic blood pressure; hs-CRP= high-sensitive C-reactive protein. \\
\hline
\end{tabular}


systolic blood pressure $(r=0.39, p<0.05)$. In contrast, none of the thrombogram values was associated with cardiovascular risk factors and inflammatory markers in the AMI group (Table 3). Thrombogram variables were not associated with the time from the diagnosis to the sample collection (data not shown).

\section{Discussion}

We found that plasma obtained from patients long after AMI showed a significantly earlier, faster and higher thrombin peak when compared to chronic stable CAD patients. These data suggest that signs of coagulation activation, as assessed by the thrombin generation test, are still present in patients long after the acute episode.

The thrombin generation test reflects the overall coagulation capacity leading to the evaluation of bleeding or thrombotic tendency (19), also providing more information about the initiation phase of thrombin formation and the overall coagulation system than routine clotting tests (4). However, no test is exempt from modifications related to the normal variability of, for instance, the concentration of coagulation factors or the presence of procoagulant microparticles (MP) (20).

After an episode of acute coronary syndrome, the occurrence of cardiac complications such as sudden death, reinfarction or recurrent chest angina, has been attributed to the development of intracoronary thrombosis $(7,8)$, which support the idea that coagulation/fibrinolysis imbalance plays a role in the complications of CAD $(21,22)$. During the acute phase of unstable angina or AMI, elevated plasma concentrations of prothrombin fragment $1+2(\mathrm{~F} 1+2)$ and fibrinopeptide $\mathrm{A}$, markers of factor Xa-mediated prothrombin activation and thrombin action on fibrinogen, respectively, have been related to an early unfavourable outcome $(16,23,24)$. In addition, Merlini et al. showed a persistent activation of coagulation in patients hospitalized for an acute coronary syndrome, which was still detectable several months after the acute event $(24,25)$.

Measurement of endogenous thrombin potential detects hypercoagulability and can be used to distinguish individuals with different thrombotic risk (3-5). The assessment of TGA in plasma from AMI patients indicated an enhanced procoagulant response as compared to stable patients, which could be due to an increase in soluble TF levels $(26,27)$ or the presence of circulating MP supporting coagulation activation (28-30).

Both CAD groups showed no differences in statin therapy although lipid levels were significantly higher in AMI patients. Since a prothrombotic effect of dyslipidemia has been reported in CAD (31), this might contribute to the increased coagulation activation in AMI subjects as compared to the stable CAD group, whereas in the latter the observed association among thrombin generation, triglycerides, fibrinogen and other inflammatory markers could point to a more proatherogenic profile.
Thrombogram values were not linearly associated with cardiovascular risk factors in the AMI group, which makes endogenous thrombin potential particularly useful in clinical practice, taking into account that up to $20 \%$ of all coronary events occur in the absence of these major risk factors (32). There is a possibility that antiplatelet agents could have an impact on thrombin generation; however, since both groups received aspirin at the time of enrolment, the effect must be similar.

The observed differences in the thrombin generation test between stable and AMI patients are not surprising. Despite common pathophysiological mechanisms (7), there is clinical evidence that atherothombosis might be a different disease to atherosclerosis. This is supported by data from the Clopidogrel for High Atherothrombotic Risk and Ischemic Stabilisation, Management and Avoidance (CHARISMA), indicating that there was no benefit among the groups of patients who had risk factors but no prior events, whereas a $12 \%$ reduction in events was observed in the groups of prior coronary, cerebrovascular or peripheral arterial disease (33). In addition, clopidogrel or GPIIb/IIIa antagonists did not suppress coagulation activation in patients with acute CAD (34-36). The fact that conventional anticoagulants failed to suppress thrombin generation in patients with established CAD in some studies $(37,38)$ also suggests a degree of overactivity of the blood coagulation system in these patients.

The study has some limitations. The TGA does not measure the cell components of coagulation, thus providing a partial view of the haemostatic system, nor does it take into account the role of inflammatory cells. The small sample size represents another limitation, although it allowed us to detect significant differences in the studied parameters. Since no sequential measurements were performed, we could not assess additional changes in the thrombin peak long after the acute episode. Finally, these results cannot be applied to other acute CAD conditions (e.g. unstable angina).

In summary, increased thrombin generation, as assessed by the thrombin generation test, is present long after acute coronary syndromes when compared to stable patients. This suggests that despite common pathophysiological substrates, AMI patients generate higher, earlier and faster thrombin, reflecting hypercoagulable/vulnerable blood. The persistence of peak thrombin over time in AMI, despite of antiplatelet and antiatherosclerotic therapy, should serve as the basis for validation of more potent antithrombotic/anticoagulant agents to prevent thrombin activation and generation among patients who are being treated medically for acute coronary syndromes.

\section{Acknowledgement}

This study was partially supported by a grant from the Ministerio de Sanidad y Consumo, Instituto de Salud Carlos III (RECAVA RD 06/0014/0008), and Gobierno de Navarra, Departamento de Salud (43/2004), Spain. 


\section{References}

1. Mann $\mathrm{KG}$, Brummel $\mathrm{K}$, Butenas $\mathrm{S}$. What is all that thrombin for? JThromb Haemost 2003; 1: 1504-1514.

2. Lane DA, Philippou H, Huntington JA. Directing thrombin. Blood 2005; 106: 2605-2612.

3. Hemker HC, Giesen P, Al Dieri R, et al. Calibrated automated thrombin generation measurement in clotting plasma. Pathophysiol Haemost Thromb 2003; 33: 4-15.

4. Hemker HC, Al Dieri R, Béguin S. Thrombin generation assays: accruing clinical relevance. Curr Opin Hematol 2004; 11: 170-175.

5. Tripodi A, Martinelli I, Chantarangkul V, et al. The endogenous thrombin potential and the risk of venous thromboembolism. Thromb Res 2007; Epub ahead of print.

6. Simioni P, Castoldi E, Lunghi B, et al. An underestimated combination of opposites resulting in enhanced thrombotic tendency. Blood 2005; 106: 2363-2365.

7. Libby P, Theroux P. Pathophysiology of coronary artery disease. Circulation 2005; 111: 3481-3488.

8. Libby P. Atherosclerosis: Disease biology affecting the coronary vasculature. Am J Cardiol 2006; 98 (Suppl): 3Q-9Q.

9. Virmani R, Burke AP, Farb A, et al. Pathology of the vulnerable plaque. J Am Coll Cardiol 2006; 47 (8 Suppl): C13-C18.

10. Naghavi M, Libby P, Falk E, et al. From vulnerable plaque to vulnerable patient: a call for new definitions and risk assessment strategies: Part II. Circulation 2003; 108: 1772-1778.

11. Naghavi M, Falk E, Hecht HS, et al.; SHAPE Task Force. From vulnerable plaque to vulnerable patient-Part III: Executive summary of the Screening for Heart Attack Prevention and Education (SHAPE) Task Force report. Am J Cardiol 2006; 98 (2A): 2H-15H.

12. Karnicki K, Owen WG, Miller RS, et al. Factors contributing to individual propensity for arterial thrombosis. Arterioscler Thromb Vasc Biol 2002; 22: 1495-1499.

13. Thompson SG, Kienast J, Pyke SD, et al. Haemostatic factors and the risk of myocardial infarction or sudden death in patients with angina pectoris. European Concerted Action on Thrombosis and Disabilities Angina Pectoris Study Group. N Engl J Med 1995; 332: 635-641.

14. Ardissino D, Merlini PA, Gamba G, et al. Thrombin activity and early outcome in unstable angina pectoris. Circulation 1996; 93: 1634-1639.

15. LopezY, Paloma MJ, Rifon J, et al. Measurement of prethrombotic markers in the assessment of acquired hypercoagulable states. Thromb Res 1999; 93: 71-78.
16. Ardissino D, Merlini PA, Bauer KA, et al. Coagulation activation and long-term outcome in acute coronary syndromes. Blood 2003; 102: 2731-2735.

17. Kalaria VG, Zoreba W, Moss AJ, et al. Gender-related differences in thrombogenic factors predicting recurrent cardiac events in patients after acute myocardial infarction; the THROMBO Investigators. Am J Cardiol 2000; 85: 1401-1408.

18. Kavsak PA, MacRae AR, Lustig V, et al. The impact of the ESC/ACC redefinition of myocardial infarction and new sensitive troponin assays on the frequency of acute myocardial infarction. Am Heart J 2006; 152 $118-125$.

19. Hron G, Kollars M, Binder BR, et al. Identification of patients at low risk for recurrent venous thromboembolism by measuring thrombin generation. J Am Med Assoc 2006; 296: 397-402.

20. Boulanger CM, Scoazec A, Ebrahimian T, et al. Circulating microparticles from patients with myocardial infarction cause endothelial dysfunction. Circulation 2001; 104: 2649-2652

21. Brodin E, Borvik T, Sandset PM, et al. Coagulation activation in young survivors of myocardial infarction (MI)-a population-based case-control study. Thromb Haemost 2004; 92: 178-184.

22. Lowe GD, Rumley A, Sweetnam PM, et al. Fibrin D-dimer, markers of coagulation activation and the risk of major ischaemic heart disease in the Caerphilly study.Thromb Haemost 2001; 86: 822-827.

23. Morange PE, Bickel C, Nicaud V, et al.; AtheroGene Investigators. Haemostatic factors and the risk of cardiovascular death in patients with coronary artery disease: the AtheroGene study. Arterioscler Thromb Vasc Biol 2006; 26: 2793-2799.

24. Merlini PA, Bauer KA, Oltrona L, et al. Persistent activation of coagulation mechanism in unstable angina and myocardial infarction. Circulation 1994; 90: $61-68$.

25. Merlini PA, Ardissino D, Bauer KA, et al. Persistent thrombin generation during heparin therapy in patients with acute coronary syndromes. Arterioscler Thromb Vasc Biol 1997; 17: 1325-1330.

26. Seljeflot I, Hurlen M, Arnesen H. Increased levels of soluble tissue factor during long-term treatment with warfarin in patients after an acute myocardial infarction. J Thromb Haemost 2004; 2: 726-730.

27. Morange PE, Blankenberg S, Alessi MC, et al.; ATHEROGENE INVESTIGATORS. Prognostic value of plasma tissue factor and tissue factor pathway inhibitor for cardiovascular death in patients with coronary artery disease: the AtheroGene study. J Thromb Haemost 2007; 5: 475-482
28. Joop K, Berckmans RJ, Nieuwland R, et al. Microparticles from patients with multiple organ dysfunction syndrome and sepsis support coagulation through multiple mechanisms. Thromb Haemost 2001; 85: 810-820.

29. Pereira J, Alfaro G, Goycoolea M, et al. Circulating platelet-derived microparticles in systemic lupus erythematosus. Association with increased thrombin generation and procoagulant state. Thromb Haemost 2006; 95: 94-99.

30. Lacroix R, Sabatier F, Mialhe A, et al. Activation of plasminogen into plasmin at the surface of endothelial microparticles: a mechanism that modulates angiogenic properties of endothelial progenitor cells in vitro. Blood 2007; 110: 2432-2439.

31. Griffin JH, Fernandez JA, Deguchi H. Plasma lipoproteins, haemostasis and thrombosis. Thromb Haemost 2001; 86: 386-394.

32. Khot UN, Khot MB, Bajzer CT, et al. Prevalence of conventional risk factors in patients with coronary heart disease. J Am Med Assoc 2003; 290: 898-904.

33. Bhatt DL, Fox KA, Hacke W, et al.; CHARISMA Investigators. Clopidogrel and aspirin versus aspirin alone for the prevention of atherothrombotic events. N Engl J Med 2006; 354: 1706-1717.

34. Eikelboom JW, Weitz JI, Budaj A, et al. Clopidogrel does not suppress blood markers of coagulation activation in aspirin-treated patients with non-ST elevation acute coronary syndromes. Eur Heart J 2002; 23: 1771-1779.

35. Mak KH, Lee LH, Wong A, et al.Thrombin generation and fibrinolytic activities among patients receiving reduced-dose alteplase plus abciximab or undergoing direct angioplasty plus abciximab for acute myocardial infarction. Am J Cardiol 2002; 89: 930-936.

36. Merlini PA, Repetto A, Andreoli AM, et al. Effect of abciximab on prothrombin activation and thrombin generation in patients with acute myocardial infarction also receiving reteplase. Am J Cardiol 2004; 93: 195-198.

37. Granger CB, Becker R, Tracy RP, et al. Thrombin generation, inhibition and clinical outcomes in patients with acute myocardial infarction treated with thrombolytic therapy and heparin: results from the GUSTO-I Trial. GUSTO-I Haemostasis Substudy Group. Global Utilization of Streptokinase and TPA for Occluded Coronary Arteries. J Am Coll Cardiol 1998; 31: 497-505.

38. Kottke-Marchant K, Bahit MC, Granger CB, et al. Effect of hirudin vs heparin on haemostatic activity in patients with acute coronary syndromes; the GUSTOIIb haemostasis substudy. Eur Heart J 2002; 23: $1202-1212$ 